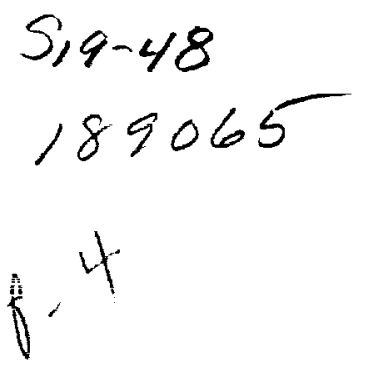

\title{
AVIRIS CALIBRATION AND APPLICATION IN COASTAL OCEANIC ENVIRONMENTS by
}

\author{
Kendall L. Carder
}

Department of Marine Science

University of South Florida

140 Seventh Avenue South

st. Petersburg, Florida 33701

\section{OVERVIEW}

The Airborne Visible-Infrared Imaging spectrometer (AVIRIS) is a test-bed for future spacecraft sensors such as the High-Resolution Imaging Spectrometer and the Moderate-Resolution Imaging spectrometers planned for the Earth observing system. To use this sensor for ocean applications, $\mathrm{S} / \mathrm{N}$ was increased by spatial averaging of images. Post-flight recalibration was accomplished using in situ the water-leaving radiance measured at flight time, modelling radiance transmission to the aircraft, and adding modelled atmospheric radiance to that value. The preflight calibration curve was then adjusted until aircraft and modelled total radiance values matched. Water-leaving radiance values from the recalibrated AVIRIS imagery were consistent with in situ data supporting the validity of the approach. Imagery of the absorption coefficient at $415 \mathrm{~nm}$ and backscattering coefficient at $671 \mathrm{~nm}$ were used to depict the dissolved and particulate constituents of an ebb-tidal esturance plume on the West coast of Florida.

\section{METHODS}

Sixteen AVIRIS data scenes were collected at about 1515 Eastern Standard Time on 4 March 1990 on a flight line across the west Florida shelf into the mouth of Tampa Bay. The following parameters were measured on the same transect covered the same day by the $R / V$ BELLOWS of the Florida Institute of oceanography: Chlorophyll a, pheophytin a , remote sensing reflectance $R_{r s}$ ' above-water downwelling irradiance $\mathrm{E}_{\mathrm{d}}\left(\mathrm{O}^{+}\right)$, subsurface downwelling irradiance $E_{d}(z)$, and subsurface upwelling irradiance $E_{u}(z)$ and radiance $\mathrm{L}_{\mathrm{u}}(\mathrm{z})$ data. Particle absorption coefficients (Mitchell 1990), detritus absorption coefficients (Roesler et al. 1989), and absorption coefficient 
due to colored dissolved organic matter (Bricaud et al. 1981) were determined.

Remote-sensing reflectance measurements (Carder and Steward 1985, Peacock et al. 1990) provided measurements which, when multiplied with modelled (Lowtran 7) total irradiance entering the sea, resulted in water-leaving radiance $L_{w}$ calculations that were consistent with the Lowtran 7 solar and atmosphere parameters. These modelled data were atmospherically attenuated and combined with radiance contributions due to reflected skylight, direct-path radiance and path radiance scattered from reflected sunlight as would be viewed by the aircraft, all calculated using Lowtran 7 code.

Diffuse transmissivity $t_{d}$ of ocean scenes from the surface to altitude can be calculated using gas absorption plus molecular and aerosol backscattering (Gordon et al. 1983). These were calculated using Lowtran 7 multiple-scattering code with a marine aerosol and a horizontal-path, boundary-layer visibility of $70 \mathrm{~km}$. Direct atmospheric path radiance, $L_{j}\left(\theta_{-}, \lambda\right)$, skylight that is specularly reflected by the sea surface and diffusely transmitted to the sensor, $\rho(\theta) t_{d}(\theta, \lambda) L_{p r}\left(\theta_{+}, \lambda\right)$, and path radiance scattered from specularly reflected, diffusely transmitted solar irradiance, $\rho\left(\theta_{0}\right) t_{d}\left(\theta_{0}, \lambda\right) L_{p r}\left(\theta_{+}, \lambda\right)$, were also calculated using Lowtran 7 . These were summed to provide the calculated total radiance $L_{t}$ available at AVIRIS:

$$
\begin{aligned}
\mathrm{L}_{t}(\theta, \lambda)=\mathrm{L}_{\mathrm{pr}}\left(\theta_{+}, \lambda\right) & \left\{\rho(\theta) \mathrm{t}_{\mathrm{q}}(\theta, \lambda)+\rho\left(\theta_{0}\right) \mathrm{t}_{\left.g_{(}\left(\theta_{q^{\prime}}, \lambda\right)\right\}}\right. \\
+ & t_{d}(\theta, \lambda) \mathrm{L}_{w}(\theta, \lambda)+\mathrm{L}_{\mathrm{p}}\left(\theta_{-}, \lambda\right)
\end{aligned}
$$

where $\rho(\theta)$ and $\rho\left(\theta_{0}\right)$ are the Fresnel reflectance values of the sea surface for reflected skylight and sunlight, respectively, and $\theta_{0}$, the solar and $\theta$ pixel-sensor zenith angles, respectively. $\boldsymbol{\theta}_{+/ \text {- }}$ are the forward $(+)$ and backward $(-)$ scattering angles involved in viewing reflected skylight and direct path radiance, respectively. Note that the observation geometry must be chosen to avoid direct sun giint into the sensor.

The reflected skylight reaching AVIRIS was determined by applying Lowtran 7 as if the sensor were on the ocean, viewing space at a zenith angle $\theta$. The reflected, downwelling path radiance, $\mathrm{L}_{\mathrm{pr}}\left(\theta_{+}, \lambda\right)$, viewed from this configuration is due to forward scattering through an angle $\theta_{+}$relative to the downwelling sunlight. This radiance was 
subsequently reduced by specular reflectance and diffuse transmittance before reaching the AVIRIS. The upwelling skylight scattered from specularly reflected sunlight is also due to forward scattering. It is similar to reflected skylight reaching AVIRIS except that it has been reduced by diffuse transmittance of the downwelling solar irradiance and by its specular reflectance prior to being scattered as path radiance to AVIRIS.

The total radiance measured by AVIRIS, $\mathrm{L}_{\mathrm{tm}}$ (St.3), at station 3 was adjusted to correspond to the radiance calculated, $\mathrm{L}_{\mathrm{fc}}$ (st. 3 ), at station 3 by multiplying by a calibration adjustment factor CAL. At all other stations AVIRIS radiance values $L_{t m}(\lambda)$ were multiplied by $C A L$, where

$$
\operatorname{CAL}(\lambda)=\mathrm{L}_{\mathrm{tc}}(\mathrm{St} .3, \lambda) / \mathrm{L}_{\mathrm{tm}}(\mathrm{St} \cdot 3, \lambda) \text {. }
$$

The water-leaving radiance for each pixel in each scene was calculated by solving Eq.1 for $L_{w}(\lambda)$, using $L_{t m}(\lambda) * \operatorname{CAL}(\lambda)$ for $L_{t}(\lambda)$. Lowtran 7 parameters determined at st. 3 for the atmosphere were used along the entire flight line to provide the atmospheric correction terms. The waterleaving radiance values determined for wavelengths greater than $800 \mathrm{~nm}$ were examined to ensure that these values did not differ significantly from zero. Had non-zero values occurred, they would have suggested that a change in visibility or aerosol optical thickness had occurred, since with water molecular absorption coefficients greater than $2.4 \mathrm{~m}^{-1}$ for these wavelengths (Smith and Baker 1981), negligible radiance leaves the water except under unusually turbid conditions.

Applications of this method will be illustrated and results shown.

\section{REFERENCES}

Bricaud, A., Morel A., and Prieur, L. (1981), Absorption by dissolved organic matter in the sea (yellow substance) in the UV and visible domains, Limnol. Oceanogr., 26: 43-53.

Carder, K.L., and Steward, R.G., (1985), A remotesensing reflectance model of a red tide dinoflagellate off west Florida, Limnol. oceanogr., 30: 286-298.

Gordon, H.R., and Morel, A., (1983), Remote assessment of ocean color for interpretation of 
satellite visible imagery: A review, Springer.

Mitchell, B.G., (1990), Algorithms for determining the absorption coefficients for aquatic particulates using the Quantitative Filter Technique, In ocean optics $x$, Proc. SPIE, 1302: 137-148.

Peacock, T.P., Carder, K.L., Davis, C.O., and Steward, R.G., (1990), Effects of fluorescence and water Raman scattering on models of remote sensing reflectance, In ocean optics $x$, Proc. SPIE, 1302: 303-319.

Roesler, C.S., Perry, M.J., and Carder, K.L., (1989), Modeliing in situ phytoplankton absorption from total absorption spectra in productive inland marine waters, Limnol. Oceanogr., 34: 1510-1523.

Smith, R.C., and Baker, K.S., (1981), Optical properties of the clearest natural waters (200-800 $\mathrm{nm})$, Appl. Opt., 20, 177-184. 